\title{
A CONSTITUIÇÃO DA SUBJETIVIDADE FRONTERIZA: DISCURSO E TRANSDISCIPLINARIDADE
}

\author{
Willian Diego de Almeida (PG/UFMS)* \\ Vania Maria Lescano Guerra (UFMS)**
}

\begin{abstract}
RESUMO: Ao lançar olhares oblíquos sob materialidades linguísticas que têm (re)circulado em nossa sociedade a respeito da mulher, é possivel dizer o quanto suas espessuras trazem enunciados atravessados por (inter)discursos $e$ o quanto as suas emergências tornam-se um testemunho que possibilita (trans)formar perfis identitários, bem como (des)legitimar as representações (históricas) dos sujeitos em uma determinada cultura. Desse pressuposto, este texto pretende problematizar, mediante recortes discursivos, a representação da mulher indígena e a constituição de uma subjetividade fronteriza, a partir da materialidade linguística da obra "Pelas Mulheres indígenas" - idealizada pela ONG Thydêwá em parceria com a Secretaria de Políticas para as Mulheres da Presidência da República, publicada no ano de 2015. Para tanto, partimos da hipótese de que a obra, apesar de incluir o gênero feminino na ordem do discurso social, acaba reforçando a marginalização da mulher de etnia indígena, através de enunciados que despontam efeitos de sentidos de exclusão, de posição de vulnerabilidade, de relações (pós)colonialistas $e$, ainda, demarcando que o seu lócus cultural fronteiriço, embora esteja em processo emancipação, ainda é visualizado como subalterno. E para que o dispositivo analítico seja empregado, utilizamos de uma proposta teórico-metodológica que preza por uma relação transdisciplinar entre: a perspectiva discursiva (CORACINI, 2007, 2010, 2011; GUERRA, 2008, 2010, 2015); a desconstrução por meio das balizagens teóricas derrideanas; o suporte teórico-metodológico foucaultiano arqueogenealógico; e, por outro fio teórico-condutor, o ponto de vista pós-colonial e o deslocamento para a análise de uma epistemologia fronteiriça (MIGNOLO, 2003, ANZALDÚA, 2005; SOUSA-SANTOS, 2010; NOLASCO, 2013). Resultados apontam que a obra (re)força a permanência do discurso colonial, como um mecanismo subjetivador que busca controlar a representação identitária de sujeitos que (mesmo falando de si) ainda estão submetidos às engrenagens da (in)(ex)clusão da sociedade hegemônica.
\end{abstract}

ABSTRACT: By throwing oblique glances under linguistic materialities that have (re) circulated in our society about women, it is possible to say how much their thickness brings statements crossed by (inter) discourses and how their emergence becomes a testimony that enables (trans)form identity profiles, as well as (de)legitimize the (historical) representations of the subjects in a given culture. Based on this assumption, this text intends to problematize, through discursive cuts, the representation of indigenous women and the constitution of a borderline subjectivity, based on the linguistic materiality of the work "For the indigenous women" - idealized by the NGO Thydêwá in partnership with the Policy Secretariat for the Women of the Presidency of the Republic, published in 2015. Therefore, we start from the hypothesis that the work, despite including the feminine gender in the order of social discourse, ends up reinforcing the marginalization of indigenous women, through statements that there are effects of meanings of exclusion, of vulnerability, of (post-) colonialist relations and, furthermore, demarcating that its border cultural locus, although it is in the process of emancipation, is still viewed as subordinate. And for the analytical device to be used, we use a theoretical-methodological proposal that values a transdisciplinary relationship between: the discursive perspective (CORACINI, 2007, 2010, 2011; GUERRA, 2008, 2010, 2015); deconstruction - through deridean theoretical frameworks; the Foucaultian theoretical-methodological support - archeogenealogical; and, on the other hand, the post-colonial point of view and the shift towards the analysis of a border epistemology (MIGNOLO, 2003, ANZALDÚA, 2005; SOUSA-SANTOS, 2010; NOLASCO, 2013). Results point out that the work (re) forces the permanence of colonial discourse, as a 
subjectivating mechanism that seeks to control the identity representation of subjects who (even speaking of themselves) are still subjected to the gears of (in) (ex) clusion of hegemonic society.

PALAVRAS-CHAVE: Análise do Discurso; mulher indígena; ex/inclusão; identidade(s).

KEYWORDS: Discourse Analysis; indigenous woman; ex/inclusion; identity(ies).

\section{CONSIDERAÇÕES INTRODUTÓRIAS}

Não é de se admirar que milhares de sujeitos, pelos clamores das "massas", têm reivindicado mudanças diante das insatisfações políticas, jurídicas e sociais, como um testemunho de dias ordinários vivenciados especialmente pelos que são oprimidos por gestos de violências, de revolta, de subcidadania; quando não dizimados pela fome, pela falta de assistencialismos, tratados como sub-humanos (SOUSA-SANTOS, 2010) por sua cor, por seu fenótipo, por sua etnia, por sua língua.

E com a finalidade de compreender a emergência dessas reivindicações, a sociedade acadêmica brasileira tem buscado, mediante estudos e pesquisas nos setores das Ciências Humanas, sobretudo na esfera linguística e, de maneira especial, no campo de pesquisa da análise do discurso, ferramentas conceituais que possam propor reflexões críticas $a$ partir de situações vivenciadas e enunciadas por sujeitos sociais considerados periféricos, seja na luta contra a exclusão, seja na busca do respeito pela diferença, pela alteridade e pela inclusão social.

Para tanto, o desassossego dessas pesquisas - sobretudo as que enunciam aversão às teorias positivistas dominantes - levaram-nos a enxergar que é através da linguagem que o sujeito se constitui e consegue edificar as suas ideias. Portanto, é por meio dela que se pode também captar, problematizar e pensar que essas reivindicações não surgem do nada, como algo que nos quer pregar uma peça. Elas estão interligadas a uma multiplicidade de discursos de outrora que remetem, inclusive, não só a aspectos locais (locis específicos), mas também fazem referência a projetos globais (MIGNOLO, 2003).

De forma sintética, tais acontecimentos e clamores não são fontes "primárias", mas sim efeitos de determinadas práticas e de movimentos discursivos, manifestados em determinadas materialidades linguísticas que são mobilizadas em nossa sociedade e que influenciam, inclusive, na constituição das identidades e como estas podem ser representadas.

Se é nas/pelas manifestações linguísticas que se despontam as identidades, pode-se dizer, então, que determinados dispositivos textuais deixam resvalar também os posicionamentos de "(des)ordem" social (FOUCAULT, 2012), o apelo às mudanças que a sociedade carece, como também denunciam ferramentas para entendermos que esses 
"sintomas" "revolucionários" são atravessados por um mosaico de (inter)discursos (PÊCHEUX, 1988). E são estes, com raízes fincadas numa memória histórica e social, que contribuem para a reprodução, mesmo que microcapilarmente, das (des)igualdades, dos aspectos culturais e das representações sociais.

Ora, isso significa que é através de determinadas materialidades que conseguimos flagrar o movimento dos discursos que estão na base da nossa sociedade e visualizar o quanto a circulação deles pode agenciar o surgimento de alguns enunciados e a interdição de outros, o estabelecimento das relações de desigualdades, as construções discursivas que temos a respeito do "eu", do "(O)outro" e do outro da exterioridade (NOLASCO, 2015, p. 48) - que foi criado, mas, paradoxalmente, esquecido, escamoteado dos/pelos discursos (pós-)modernos.

E ao acolher esse gesto de interpretação, uma obra escrita por mulheres indígenas, por exemplo, passa a não ser mais vista como uma simples ocorrência, mas, sim, como um acontecimento discursivo articulado por práticas discursivas. Sua "aparição" passa a funcionar como um efeito discursivo, uma estratégia necessária por aqueles que têm o poder de "instituir verdades" (FOUCAULT, 2010), de abrigá-las e de dissimulá-las (DERRIDA, 2001, p. 13), como um dispositivo social que molda e "confere" às mulheres indígenas uma determinada identidade, isto é, associa a elas uma possível representação.

E para avançar nessa discussão, este texto pretende problematizar, mediante recortes discursivos, a representação da mulher indígena e a constituição de uma subjetividade fronteriza, a partir da materialidade linguística da obra "Pelas Mulheres indígenas" idealizada pela ONG Thydêwá em parceria com a Secretaria de Políticas para as Mulheres da Presidência da República, publicada no ano de 2015.

Para entender sobre a materialidade, esclarecemos que no ano de 2015, a ONG Thydêwá (www.thydewa.org/thydewa) realizou um projeto designado "Cantando as culturas indígenas", patrocinado pelo BNDES com a publicação da obra "Pelas Mulheres Indígenas", com parceria da Secretaria de Políticas para as Mulheres da Presidência da República e Secretaria de Políticas para as Mulheres da Bahia. Esse projeto, tendo como responsável o representante da instituição Sebastián Gerlic, buscou angariar o valor total de $\mathrm{R} \$ 329.561,40$ para o seu desenvolvimento, estando este ligado aos direitos humanos, coletivos e ao fortalecimento cultural. Buscando justificar a afirmação de que se os indígenas já sofrem discriminação, as mulheres indígenas têm sofrido muito mais no âmbito público, social e familiar, o objetivo geral do Projeto Base (THYDÊWÁ, 2015, p. 16) reside em "Fortalecer Mulheres Indígenas de oito etnias do Nordeste na pesquisa, no estudo e na promoção de mudanças para as realidades de suas comunidades (www.mulheres indígenas.org).

A partir do pressuposto, dos objetivos e da materialidade, articulamos a hipótese de que a obra, apesar de incluir o gênero feminino na ordem do discurso social, acaba reforçando 
a marginalização da mulher de etnia indígena, através de enunciados que despontam efeitos de sentidos de exclusão, de posição de vulnerabilidade, de relações (pós)colonialistas e, ainda, demarcando que o seu lócus cultural fronteiriço, embora esteja em processo emancipação, ainda é visualizado como subalterno.

E para que o dispositivo analítico seja empregado nos recortes selecionados, utilizamos de uma proposta teórica e metodológica que preza por uma relação transdisciplinar entre perspectiva discursiva e outras áreas do conhecimento. Portanto, nos posicionamos a favor da heterogeneidade teórica, não por mero capricho, mas por compreender que a confluência de teorias passa a ser uma exigência requerida pelos próprios recortes, uma vez que visa auxiliar o gesto de interpretação discursiva.

Assim, alguns diálogos tornam-se necessários, em particular o estabelecido pela confluência de quatro perspectivas:

1) A perspectiva discursiva (CORACINI, 2003, 2007, 2010; GUERRA, 2010, 2015), a fim de produzir um outro lugar de conhecimento, afastando-se da mera aplicação da linguística sobre as ciências sociais ou vice-versa nos enunciados analisados;

2) O suporte teórico-metodológico foucaultiano $(1988,2008,2010,2012)-$ arqueogenealógico - que está na base da teórica da perspectiva discursiva, contribuindo para a constituição de um dispositivo analítico, um modo de ler os efeitos de sentidos dos recortes da obra, por meio de uma atividade de investigação (escavação) que nos permite observar fatos desconsiderados, escamoteados, formações e memórias discursivas, bem como a manifestação de poderes e saberes que estão no bojo da discursividade da obra;

3) Da desconstrução, por meio das balizagens teóricas derrideanas (1991, 2001, 2003, 2013), sobretudo pela análise de deslocamentos das significações, no descentramento dos signos;

4) E de outro fio teórico-condutor: o ponto de vista pós-colonialista de Anzaldúa (2005), de Mignolo (2003), de Sousa Santos (2010), Nolasco (2013), uma vez que articulam um deslocamento para a análise de uma epistemologia fronteiriça.

Essas diferentes paternidades teóricas justificam-se por suas singularidades, como um dispositivo de interpretação dos recortes elencados na obra "Pelas Mulheres Indígenas" (2015) em relação à mulher indígena, "entre áreas do conhecimento que se cruzam sem se superporem, distinguem-se sem serem inteiramente distintas - teorias do discurso de orientação francesa, filosofa e psicanálise de orientação lacaniana". (CORACINI, 2010, p. 92).

\section{TRANSDISCIPLINARIDADE E A VISADA DISCURSIVA}


A centralidade analítica das materialidades da obra "Pela Mulheres Indígenas" (2015) exige que determinadas noções teóricas venham à tona, o que não tem relação alguma com a questão da desvalorização teórica de outros campos. Tanto é que muitos conceitos derivados dessa própria área não foram tratados aqui pelo fato de os processos discursivos assim não o exigirem. E essa compreensão é fundamental justamente para entender que, ao "chegar em um determinado ponto", a perspectiva discursiva passa a necessitar do diálogo com outras áreas de estudo, mas não as captando em sua integralidade, apenas trazendo as noções teóricas que solidificam o gesto de interpretação analítico-discursivo em aspectos pontuais, específicos. Daí a ideia de Coracini (2010, p. 92-93) ao dizer que acabamos por "puxar os fios de que necessitamos, para, com eles, tecermos a teia de nossa rede teórica, transformando, assim, esses fios, ao mesmo tempo em que nosso olhar é por eles transformado". São esses fios que nos ajudam a analisar a materialidade linguística.

E esse desafio se pauta na ideia de que transdisciplinarizar é indicar que não existem fronteiras entre as disciplinas e, por isso, uma abordagem “pluralista”. E esta, por sua vez, não visa privilegiar uma determinada teorização, mas indicar a ideia de que as que foram trazidas para a cena que se utiliza do olhar discursivo, são evocadas em razão das próprias nuances discursivas dos dados aqui elencados, já que são estes que de fato definem o objeto de pesquisa, pois eles não lhe preexistem. Mais precisamente, é o ponto de vista que constrói um corpus, que não é um conjunto pronto para ser transcrito.

Nessa proposta, os aspectos teórico-metodológicos discursivos não pressupõem o olhar discursivo como o centro e outras teorizações como periféricas, sendo estas utilizadas apenas como "muletas" conceituais ou, quando não, como noções teóricas que ficam na "sala de espera" disponíveis para ser aplicadas e "ajudam" apenas a enriquecer o conhecimento-regulação articulado pela "disciplina-mãe". Esclarecemos isso a fim de descartar a possibilidade de imperialismo cognitivo, assinalando que não existe glamour nenhum em analisar discursivamente, por exemplo, a materialidade linguística da obra "Pelas Mulheres Indígenas" (2015) pensando somente em noções teóricas unívocas. Isso porque se quiséssemos que imperasse somente determinadas disciplinas, sejam as do Norte, sejam as do Sul (SOUZA SANTOS, 2019, p. 11), estaríamos também tecendo um certo imperialismo cognitivo, sob o manto da justificativa de que só é possível pensar pontos discursivos " $\mathrm{x}$ " com olhares " $\mathrm{y}$ ".

Decidimos, então, utilizar as bases um novo gesto analítico que propusesse em sua base a contribuição de várias perspectivas teóricas capazes de apreender e denunciar o funcionamento discursivo dos recortes que compõem este texto e que fazem parte da realidade de uma sociedade como a brasileira. Nessa nossa leitura de "entremeio", isto é, no campo relacional com outras esferas epistemológicas (ORLANDI, 2003, p. 3), não nos ocupamos da ideia de que somente um conhecimento é exclusivamente válido. Em decorrência disso, buscamos realizar uma "travessia da tormenta" (ROUDINESCO, 2007, p. 11) e trazer teorizações que se confrontam em muitos pontos, mas que também 
estabelecem diálogos muito efetivos com perspectiva discursiva. Teorizações constitutivas, inclusive, de uma heterogeneidade teórica, na qual o pensamento crítico de uns se efetiva por meio do atravessamento de outros, de maneira indelével. E esse gesto, longe de realizar meras aplicações teóricas, serve para explicar que é o corpus que vai evocar a emergência das teorias e não as teorias que vão se aplicar ao corpus.

Como o processo analítico empreendido pela perspectiva discursiva não se dá mediante a compartimentalização de vertentes teóricas unívocas, mas por meio do entrelaçamento entre o linguístico com o social, vale dizer que as vertentes podem ser diferentes umas das outras, porém devem dialogar entre si, em razão do gesto de interpretação do analista ocorrer, sobretudo, não só pela "ordem da estrutura, mas da materialidade [...]" (POSSENTI, 1988, p. 201).

Coracini (2003, p. 27) justifica a defesa da constituição e do avanço da perspectiva discursiva, inclusive demonstrando esse progresso ao postular em suas pesquisas como visada discursivo-desconstrutiva. A autora faz isso por considerar que somos sujeitos que (sobre)vivem no bojo de um sistema neoliberal e que, portanto, esse campo teórico de análise vai se relacionar fortemente "a ideologia da globalização que invade o mundo, define posições, demarca relações de poder, cava ainda mais as desigualdades sociais econômicas e sociais".

A justificativa da autora deu-se também pelo fato de as teorias críticas - sobretudo depois da década de 60 - terem sofrido diversas rupturas epistemológicas que começaram a tomar conta de diversos cenários de pesquisas, sobretudo no campo linguístico. E essa questão, por sua vez, acabou "atingindo" o campo acadêmico, sobretudo nas reflexões teórico-metodológicas e nas pesquisas, tanto nos objetos de análises quanto nos próprios processos e conceitos. Compenetrado nesse movimento, o olhar discursivodesconstrutivo, seja pelas mudanças sociais, seja pela ampliação das abordagens epistemológicas, visa reconhecer o caráter transdisciplinar do processo analítico, sendo este empreendido com o objetivo de mediar o movimento interpretativo sustentado, sobretudo, pelos princípios gerais da Análise do Discurso, da desconstrução, do suporte arqueogenealógico foucaultiano e demais orientações epistemológicas que colaborarem com a análise discursiva.

No caso deste artigo, pensamos ser relevante não banalizar o conceito de transdisciplinaridade e, por isso, propomos pensar numa perspectiva discursiva que dialogue com outras áreas de conhecimento, como as Epistemologias do Sul (SOUZA SANTOS, 2019, p. 20), uma vez que elas articulam também aspectos discursivos que estão intrinsicamente incorporados em suas práticas sociais. São teorizações que estão relacionadas às propostas de teóricos pós-coloniais, os quais pensamos, entre (du)elos, relacionar conforme a solicitação discursiva do recorte da materialidade. 
Além do mais, a utilização de uma crítica que procure "escavar" (FOUCAULT, 2008, p. 8) mais propriamente as discursividades por meio da exterioridade, pelas críticas "forado-eixo" (NOLASCO, 2013, p. 47; 2016, p. 57) torna-se importante, pois além de compreendermos melhor os (inter)dirscuros que estão na base do aparecimento da materialidade da obra "Pelas Mulheres Indígenas" (2015), podemos analisar o quanto há "negociações" discursivas em seus enunciados. E são essas negociações, por sua vez, que garantem a visibilidade, a re-tomada e a re-circulação de determinados discursos que incidem na identificação simbólica, nos papéis sociais, na representação identitária, por exemplo, da mulher indígena que intervém na disposição das subjetividades.

Essa inter-relação entre perspectiva discursiva, os "desconstrutores" e epistemologias outras não pressupõe uma teoria a priori, mas sim, um imperativo de ordem metodológica de análise das discursividades: o empreendimento de um "vai e vêm", sempre que necessário, da teoria em razão do recorte discursivo.

Distantes de colocar "qualquer" recorte discursivo sob um mesmo rótulo teórico-analítico com um "pretexto" de simplificar a aplicabilidade teórica, esse olhar que buscamos aqui delinear é justamente para exercer um gesto analítico que considera a pluralidade de polos epistemológicos, mas não de maneira hierarquizada, polarizada e essencialista.

Concordarmos com Mignolo (2008, p. 291) quando explica que "[...] hoje não há algo fora do sistema; mas há muitas exterioridades, quer dizer, o exterior construído a partir do interior para limpar e manter seu espaço imperial". Além do teórico argentino, também aplaudimos Souza Santos (2008, p. 24), ao dizer que "[...] é difícil conceber uma alteridade ou exterioridade absoluta à modernidade ocidental. "E esse gesto se dá porque entendemos que a perspectiva discursiva "é um lugar de discussão constante sobre a construção dessa transdisciplinaridade: língua, sociedade, historicidade, sujeito são os polos em torno dos quais vem sendo erigido o seu edifício teórico [...]" (GREGOLIN, 2006, p. 85). E é no campo desse desafio teórico - ou da incompletude constitutiva seus outros olhares teóricos - que também buscamos nos assentar e apontar como não há um lugar "disciplinar" estabelecido que deve ser considerado inerente ao gesto analítico discursivo.

Se há a necessidade de se trazer outras bases teóricas, conceitos e objetos de pesquisas específicos, como já mencionado, a prática de utilizá-los como um instrumental teórico só pode se dar mediante o processo de trandisciplinarização. Metaforicamente, pode-se comparar com a montagem de um mosaico, cuja técnica incide em encaixar peças diversas, de ângulos diferentes com o objetivo de formar algum tipo de imagem ou figura a ser construída.

A metáfora do mosaico é a que mais se aproxima da visada teórica transdisciplinar, pois nesse gesto de encaixe pensa-se não só na representação a ser construída, mas também na 
harmonização das peças, na instalação de na mobilização de um saber que se quer repassar. E esse aspecto é que motiva um analista a evocar outras noções teóricas que possam considerar a relação de interpretação estabelecida entre as expressões, e os seus efeitos de sentido. Isto é: "[...] quando o corpus a ser analisado estiver sob determinadas condições de produção e quando interessar um enfoque determinado [...]" (POSSENTI, 1988, p. 114). Daí, transdisciplinarizar:

[...] não se trata de recorrer a outras disciplinas, menos ainda de nos servirmos, enquanto analistas de discurso, de cada uma tomando-as na sua integralidade, como pretende uma certa interdisciplinaridade, sem atentar para a impossibilidade de tal empreendimento, mas de puxar os fios de que necessitamos, para, com eles, tecermos a teia de nossa rede teórica. (CORACINI, 2010, p. 93)

Por esse motivo, alicerçamo-nos nesse campo transdisciplinar entre perspectiva discursiva, desconstrutores e teorização pós-colonial, uma vez que, além de buscarmos questões e aspectos que outro analista ainda não desenvolveu, possibilita-nos delinear novas formas de encarar a(s) configuração(ões) dos saberes, considerando o recorte, as condições de produção, a enunciação, a hipótese, os objetivos e as perspectivas traçadas em nosso texto; aspectos essenciais para se ter acesso aos efeitos de sentido outrora deixados à margem e des-cobrir como estes se desenvolveram, se constituíram, se deslocaram e (re)produzem saberes que adquirem um espessura material.

No que tange à perspectiva discursiva, esta vai nos auxiliar apreender a constituição do sujeito, a importância de se analisar que nenhum enunciado está solitário, mas, sim, que está solidariamente coligado a outros enunciados, isto é, aos interdiscursos, e o quanto estes contribuem para a edificação das identidades e a "ficção" da autoria -, há a necessidade ampliarmos essa compreensão para que outras negociações de sentidos sejam verificadas, "outros jogos de polissemia, choques de temporalidades em constante processo de transformação, responsáveis em última instância pela sucessão de configurações hermenêuticas que de época para época dão corpo e vida a tais identidades [indígenas]" (SOUZA SANTOS, 2013, p. 167).

Inseridos nessa discussão, o olhar foucaultiano e a perspectiva teórico-filosófica derrideana estabelecem diálogos com os estudos das discursividades, pois seus olhares contribuem para a desconstrução do logos cognitivo. Foucault por problematizar a constituição dos discursos, o questionamento dos saberes, das nossas práticas, dos (novos) objetos discursivos (a indígena como escritora...), os recortes disciplinares e a (des)valorização das verdades universais.

Já Jacques Derrida por apontar como as palavras não podem ser lidas ipisis litteris nem ipisis verbis, pois elas sempre fazem referência a uma questão ficcional, 
fantasmagórica, possuindo um lado phármakon (DERRIDA, 2005, p. 14). E, por isso, a escrita (portadora e devedora de sentidos) de uma lei de e de uma obra, por exemplo não podem assumir um significado transcendental, imune a interpretações, fiel às verdades. Logo, em relação à obra "Pelas Mulheres Indígenas", os enunciados não são literais, pois não coincidem com aquilo que parece a sua literalidade ou intencionalidade buscam denunciar, por isso, a sua leitura pode ser considerada uma produção de sentido.

Já em relação Nolasco (2013), Anzaldúa (2005) e Souza Santos (2013), as suas interlocuções estabelecidas do outro lado a esfera metropolitana e hegemônica da sociabilidade ocidental, cuja epistemologias outrora deixadas à margem, cada uma com suas particularidades, devem ser trazidas à tona. Ele trabalha com uma opção descolonial (MIGNOLO, 2008, p. 291), e nos ajuda a pensar como a produção social de sentidos e a constituição de determinadas materialidade devem ser consideradas não sobre essas regiões epistemológicas dominantes, mas a partir das regiões epistemológicas fronteiriças. E esse trajeto de sentido influi no gesto de interpretação da obra "Pelas Mulheres Indígenas", pois concebe os olhares analíticos em uma manifestação discursiva assentada numa experiência epistemológica mais concreta, "a partir das línguas e das categorias de pensamento não incluídas nos fundamentos dos pensamentos ocidentais" (MIGNOLO, 2008, p. 305).

Dos recortes selecionados para o processo analíticos vemos a necessidade de pensar a partir de um determinado locus geoistóico muito particular, que necessita de uma orientação epistemológica crítica subalterna, fronteiriça e pós-colonial advinda daqueles que têm gravado em seus corpos e em suas memórias discursivas a marca imposta pelo golpe do martelo imperial ocidental.

Portanto, como explicar a produção se sentidos a partir de perspectivas teóricas dos grandes centros sendo que o próprio discurso da obra emergiu de uma realidade epistemológica, política e cultural desfamiliarizada da realidade do império cognitivo logocêntrico? Parece-me, contudo, necessário então recorrer às teorizações que expliquem "esse lado da linha" (SOUZA SANTOS, 2019), para que os gestos interpretativos não caiam nos pressupostos ou aprióris históricos universalizantes ditados pelos grandes centros.

Sejam pós-modernistas, sejam pós-colonialistas, esses teóricos contribuem para dois pontos: os primeiros, para que a visibilidade das verdades e dos discursos imperativos racionalizados como naturais sejam descontruídos, desmistificados, desnudados, desmascarados; o segundo, a fim de articular uma teorização oriunda de crítica pós-colonial que esteja baseada em epistemologias não nortecêntricas, a fim de trazer à tona a voz daqueles que (sobre)vivem pela insígnia colonial, para que os discursos, as experiências e as subjetividades não sejam enraizados nas categorias dominantes (MIGNOLO, 2008, p. 288), pensando a partir da paragem específica em que o discurso foi enunciado. 
Com essa (com)fusão teórica solidária, esse imbricamento de ideias, consegue-se investigar a manifestação discursivo presente nas materialidade da obra "Pelas Mulheres Indígenas", a fim de desmantelar o perigo de uma história universalizante, questionar a objetividade e a evidência dos dados e dos fatos históricos que por séculos têm sido construído como uma via de "acesso à verdade" e encampado a nossa realidade, na qual a própria mulher indígena, por muito tempo, não contava...

\section{O PROCESSO ANALÍTICO DA CONSTITUIÇÃO IDENTITÁRIA DO SUJEITO FRONTEIRIZO}

Para o processo analítico deste artigo mobilizamos dois recortes, diante da extensão deste trabalho. Inicialmente, o recorte (R1) da obra em foco articula saberes que nos levam a efeitos de sentidos de exclusão da mulher indígena em relação ao "esquecimento" do Estado, demonstrando a presença das relações de poder, a saber:

\section{PMI (R1) Vemos atualmente o governo querendo continuar a massacrar os indígenas. Parece que os homens ambiciosos por dinheiro quer fazer o fogo voltar contra nós. \\ [...]}

A gente quer que o governo tenha compromisso, que entregue nosso território de volta. Só assim todos que vivemos na região teremos paz. (ONG THYDÊWÁ, 2014, p. 16)

Em R6, podemos observar o quanto a materialidade linguística pode trazer a descrição de acontecimentos pretéritos que parecem emergir como uma possibilidade de resistência às mudanças globalizantes que têm ocorrido no hemisfério Sul. Como os gestos de interpretação da história indígena no Brasil foi/é (re)vivido e (re)construído por meio de diversas manifestações linguísticas, com a materialidade da obra analisada isso não seria diferente. Ela está umbilicalmente ligada aos atravessamentos discursivos e funciona como um instrumento de escrita capaz de trazer à tona formações discursivas e interdiscursos que sustentam o seu dizer e alimentam as representações que temos, por exemplo, de que as mulheres indígenas e o seu povo ainda são ignorados ou legitimados como minoria pelos movimentos governamentais.

E é nesse contexto que R1 traz para a cena da enunciação os desafios pelos quais os indígenas têm passado e a necessidade de resistir (FOUCAULT, 1988, p. 91) como forma de resposta à sua própria sobrevivência. Além disso, R6 discursiviza o quanto o gesto de governamentalidade - as instituições, os procedimentos, os gestos analíticos, táticos e reflexivos do governo (FOUCAULT, 2012, p. 296) - tem atuado em suas vidas.

Nessa escritura, quando um verbo como o "vemos" é utilizado no modo indicativo (certeza, convicção), o enunciador traz para a cena da enunciação uma ideia de que o sujeito não mobiliza o seu dizer apenas como um sujeito qualquer, pois a expressão 
identifica que ele fala a partir do interior de um grupo. O item lexical "vemos", utilizado na primeira pessoa do plural, faz entrever não só a possível instância espacial enunciativa dos acontecimentos (fora da zona urbana), como também identificar o processo temporal por meio do advérbio de tempo "atualmente".

A materialidade discursiva dessa expressão "coletiva" torna-se absolutamente particular (PÊCHEUX, 2012, p. 21), pois ao enunciar "atualmente o governo querendo continuar", $\mathrm{R} 1$ deixa resvalar efeitos de sentido de relações de poder entre os que dominam (centros hegemônicos, homem branco) e os que são dominados (indígenas). Essa relação de dominação reavivada pela memória discursiva colonial é denunciada através do advérbio "atualmente" e dos operadores linguísticos "querendo" (gerúndio, continuidade) e "continuar" (forma nominal do verbo) que esses eventos permanecem ocorrendo nos dias atuais e que não foram superados, demarcando inclusive a próprio "sujeito paciente": "os indígenas".

R1 operacionaliza sentidos. Existem aí dois "antagonistas": o governo e os "homens ambiciosos" (sinônimo para branco). De acordo com Potiguara (2004), é fácil notar que as causas de muitos conflitos para com os indígenas vêm desde o processo de colonização. Violência, racismo e intolerância fazem morada nas aldeias nas indígenas quando se referem ao contato com o governo e com o branco. Para a autora indígena (2004, p. 222), esse "paternalismo oficial" advindo dos órgãos públicos sempre foi e ainda é uma forma de violência e de racismo institucional, nos quais as mulheres e as crianças passam a serem os mais alcançados.

Em relação aos "homens ambiciosos", quando R1 enuncia esses termos para interpretar de forma eufemística os brancos gananciosos, a sociedade hegemônica capitalista, deixa resvalar efeitos de sentidos de dominação e de exploração, identificando que esses sujeitos estão dispostos a qualquer atitude para que possam alcançar o aspecto financeiro almejado. Ancorado numa formação discursiva financeira e econômica, o enunciador projeta que a ideia de invasão capitalista no território indígena tem sido grande e voraz em razão da questão financeira.

Trata-se de um argumento um tanto convincente da cultura ocidental que serve como pretexto para o desrespeito da différance (DERRIDA, 1991, p. 47), para a continuidade da primazia hegemônica com base na discriminação e na manutenção de uma memória colonial arraigada de sucessivos artifícios de exclusão. De acordo com GUERRA (2015, p. 98), as comunidades indígenas contemporâneas espelham um histórico de massacres e de exploração que perpassou seu contato com o colonizador, uma vez que as terras garantidas aos índios não são suficientes para a manutenção de sua cultura. A questão aqui não é só pensar na exclusão do indígena; é analisar que as próprias discursividades que estabelecem interlocuções com as relações de poder entre o governo e a população indígena é que têm consolidado esse gesto de exclusão (GUERRA, 2015, p. 99), já que toda produção tem que ter em mente o lucro diante do capitalismo. 
Ao enunciar de forma declarada os algozes, o enunciador faz um gesto de "resistência às captações do poder" hegemônico (FOUCAULT, 1988, p. 147), atentando para a impossibilidade de continuar esse jogo que remete à retórica colonial, na qual determinadas práticas bárbaras de colonização eram realizadas contra eles. E esse gesto de resistência é observado também como um ato de enunciar que a invisibilidade desses processos de violência e de exclusão, ambos associados à ganância pela tomada de terras e à vontade de extermínio de povos e culturas, já não pode se sustentar mais.

E esse gesto de indignação também pode ser analisado na rogativa "governo tenha compromisso" e "entregue nosso território de volta". R1 busca reivindicar um direito que é próprio dos indígenas: o seu espaço, o seu território, já que a terra é um bem ancestral para as etnias indígenas, sendo a sua principal bandeira a luta pelo território na busca pelo bem viver (GUERRA, 2010, p. 30-31). Ao analisarmos a expressão "governo tenha compromisso", o enunciador utiliza um tom de denúncia a fim de que haja uma subversão em relação às atitudes governamentais para com os povos indígenas. Quando isso ocorre, é possível flagrar a perversidade em se utilizar da degradação dos inúmeros costumes e culturas indígenas, provocada pela sociedade envolvente, o poder econômico, para negar aos povos indígenas a sua própria condição e os direitos que dela seriam decorrentes, a sua própria história.

Com Souza Santos (2014, p. 11) é possível dizer: “[...] a promessa de igualdade nunca passou de uma fantasia jurídica", pois, infelizmente, os povos que têm referências não ocidentais acabam sofrendo com o domínio hegemônico. E isso se confirma em R1, pois pelo próprio recorte é possível depreender a ideia de que o próprio Estado parece se utilizar de artifícios vigorosos para demonstrar que ainda vigora um processo de controle "administrativo", baseado na presença de uma hierarquia que já não se manifesta pelo quadro das opressões declaradas, deixando manifesto: o deste lado da linha (o homem banco) e o do outro lado da linha (o sujeito indígena) (SOUZA SANTOS, 2007, p. 71) que desaparece perante a sua realidade de fronteiriça (ANZALDÚA, 2005, p. 704; NOLASCO, 2009, p. 44).

Com Nolasco (2009, p. 40), vemos que a obra coopera para a manutenção de uma "[...] prática de exclusão efetuada por uma narrativa discursiva belamente construída de forma a deixar de fora, sem dó nem piedade, todos aqueles sujeitos que já tinham sido, por antecipação, condenados a não fazer parte da história ocidental[...]”.

E esse gesto de controle não para por aí. A discursividade dos enunciados da obra "Pelas Mulheres Indígenas" (2015) pode retratar inclusive outros deslizamentos de sentidos que remetem não só ao "esquecimento" do Estado, demonstrando a presença das relações de poder, mas também a (in)visibilidade do sujeito indígena, que pode ser observada no recorte (R2), a seguir.

PMI (R2): O Fogo de 51 
Foi uma coisa muito horrível para as mulheres indígenas... Houve muito estupro, até de índias grávidas e de mulheres em resguardo. Os policiais usaram elas. Judiaram delas. As nossas mulher foram muito humilhadas. Amarraram seus maridos perto delas enquanto eram usadas. Tem mulher que ainda hoje se sente envergonhada. Nós, mulheres, somos muito sofridas. Ainda hoje passa muito essa coisa de estupro. Foi lá que começou essa violência que ainda existe contra nós, mulher indígena. Quando a polícia chega nas nossas áreas é com muita agressão, agressão contra as mulheres e contra as crianças também. Agressão verbal e física. $\mathrm{Na}$ nossa comunidade, mulheres e crianças também lutam para defender nosso território. Nós, mulher, bota o maracá e a borduna na mão e enfrenta o que for. (ONG THYDÊWÁ, 2015, p. 13)

Em R2, na esteira da perspectiva gramatical de Neves (2000, p. 791), é possível analisar que enunciador mobiliza os verbos no pretérito perfeito - foi, houve, usaram, judiaram, foram, amarraram, eram - a fim de apontar para os eventos percebidos como pontuais e simultâneos. $\mathrm{O}$ uso desses verbos remete a fatos passados e nos permitem interpretar que há uma memória discursiva, cujo trabalho produz, como um domínio associado, a ligação da singularidade do acontecimento discursivo "Fogo de 51" com a atualidade. Isto é, do intradiscurso (enunciado) emergem efeitos de sentidos de sofrimento, de luta, de submissão, de dominação em decorrência da sua relação com o interdiscurso (préconstruído, já-lá) (PÊCHEUX, 1988), buscado nos resquícios da memória discursiva.

No âmbito dos estudos fronteiriços, com Anzaldúa (2005, p. 706) vemos a possibilidade de ressaltar dois aspectos: que essa narratividade funciona como uma prova à intolerância do ambíguo, do diferente vivenciado (e ainda vivido...) pelos sujeitos periféricos; mas, por outro lado, traz à tona cenas, via memória discursiva, de um momento histórico - "Fogo 51" - em que ainda não era desconstruída a dualidade sujeito-objeto, que matinha a mulher, o sujeito indígena, como uma vida matável. Portanto, o uso de termos que indicam uma ação passada denuncia aspectos para além de um registro histórico ingênuo e simplista. $\mathrm{R} 2$, ao enunciar uma narratividade que se refere ao passado, aponta para a relação das forças sociais existentes entre o branco versus o indígena, o colonizador versus o colonizado, o forte versus o "fraco".

Vale dizer que não é apenas essa imagem de rivalidade amigo-inimigo que é trazida e reforçada em R2. Há também a imagem de zóe-bíos, de vida nua-existência política, de exclusão-inclusão, articuladas por Agamben (2010, p. 16). Isto é, a vida da mulher indígena (vida humana) é incluída na ordem do discurso social unicamente sob forma de sua exclusão. Trazendo para a especificidade desse excerto, e com um olhar transdisciplinar, compreendemos essa vida matável com Agamben (2010), que traz o termo homo sacer, remetendo a um poder soberano jurídico que (trans)forma, pela ordem 
de sua força, um sujeito excluído da ordem discursiva social como um sujeito possível de ser aniquilado, com uma vida indigna de ser vivida.

No enunciado, os efeitos de sentido de homo sacer denunciam que "[...] existem vidas humanas que perdem a tal ponto a qualidade de bem jurídico, que a sua continuidade, tanto para o portador da vida como para a sociedade, perdeu permanentemente todo o valor" (AGAMBEN, 2010, p. 133). E como os sujeitos são efeitos dos discursos que circulam na trama social, os próprios discursos é que elencam quem é (ou será) seu homo sacer, ou um grupo de sujeito, uma comunidade. E é por essa constante ameaça em relação a sua vida ser matável, o homo sacer, que em R2 o enunciador necessita trazer essa relação do passado, tensionada pela memória discursiva, como uma introdução para falar de si.

Isso porque $\mathrm{R} 2$ enuncia, desde o início do excerto, termos que acarretam um caráter de afastamento do enunciador em relação ao fato enunciado. Apesar disso, há mudança em sua fala, uma aproximação de sua ipseidade (DERRIDA, 2003), no momento em que traz para o seu gesto de enunciação o pronome pessoal do caso reto, "nós", primeira do plural - cuja função é a de substituir os nomes para assumir a posto de sujeito da ação - e o "ainda" - advérbio de tempo que traz a função juntiva (NEVES, 2000, p.273) como um artifício de que, ao falar do outro, também fala si; que ao fazer emergir o passado demonstra que esse fato ainda está recorrente em seu presente.

$\mathrm{O}$ acontecimento narrado possibilita um processo de identificação do enunciador pelo fato de também ser indígena ou, como diria Coracini (2010, p. 95), permite "pontos de identificação com o outro: traços no sujeito que se identificam com traços do/no outro". Esse gesto também aponta para a ideia de pertencimento, não no ius sanguinis ou ius solis, mas ao identificar que, por meio do fato de enunciar o acontecimento relacionado ao outro, ela também fala de si, mesmo que imaginariamente, uma vez que o "Fogo de 51" traz de forma indelével uma marca na vida daqueles de etnia indígena que vivem na região bahiana.

Na esteira de Anzaldúa (2005, p. 707), pode-se dizer que R2 seria um apelo, uma maneira de denunciar a necessidade de mudança para essa realidade e de cicatrizar a divisão existente, esse mal-estar entre culturas que, embora saibamos que nunca vai desaparecer, em razão dos próprios fundamentos de nossas vidas, da nossa cultura, das nossas línguas, dos nossos pensamentos, pode gerar movimentos sociais. Esses movimentos, aos poucos, podem transformar essa forma massiva de pensamento dualista no sujeito e na consciência coletiva. Esse excerto representa a continuidade de uma longa luta que ainda teima em prevalecer no nosso seio social, mas que poderá, com a melhor das esperanças, trazer o fim do estupro, da violência e da guerra.

Pensando ainda em R2, pelo fato de o excerto ter sido escrito por um sujeito-enunciador que ocupa o lugar dos oprimidos, é impossível não verificarmos o tom de crítica negativa adotada em relação às atitudes de dominação e de exploração em relação aos povos 
indígenas, demonstrando dois pontos analíticos: as suas lutas não podem ser vistas de maneira separada das lutas sócio-políticas articuladas pelas ocorrências sociais do branco - embora já tivessem sido tendenciosamente caladas; as mulheres indígenas são produtoras de um saber e, portanto, a sua função enunciativa realça não só a força e a presença dos oprimidos em nossa sociedade como também dá ênfase a uma nova orientação epistemológica de manifestação consistente: uma crítica fronteriza (NOLASCO, 2013), pois se esquiva de ser um produto imperial-hegemônico.

Souza Santos (2019, p. 17) contribui para pensarmos sobre esse gesto de trazer o conhecimento de "determinadas verdades" à tona. Com o autor, vemos que essa estratégia de considerar a voz dos sujeitos já oprimidos durante muitos anos, permitindo que eles falem de si, da representação do seu próprio mundo utilizando dos seus próprios termos, subjaz às mudanças que a nossa sociedade tem presenciado: de que as mulheres, sobretudo as indígenas, não são pobres de experiências (ANZALDÚA, 2005, p. 235), tendo o poder de falar e o respeito de serem ouvidas; e que, por isso, elas produzem conhecimentos, epistemologias outrora renegadas pela ignorância hegemônica e colonialista assentada pela modernidade ocidental.

Da sua fala são apreendidos mecanismos discursivos que, ao serem enunciados, acabam funcionando como estratégias para a constituição de sua própria subjetividade, apoiando, em nosso imaginário, sobre qual o lugar que as indígenas ainda ocupam em nosso espaço discursivo e social: o periférico, o marginalizado, o excluído.

Com Souza Santos (2019), podemos pensar que essa discriminação vem há muito tempo sendo mantida pela desigualdade, mas, sobretudo, pela exclusão social. Para sociólogo a desigualdade social está ligada ao fator de integração social, dinamizando a ideia de que quem está "abaixo" no sistema hierárquico de uma sociedade ainda está dentro desse próprio sistema, pois a sua presença é indispensável para uma integração subordinada.

\section{EM BUSCA DE ARREMATES FINAIS}

Levando em consideração a hipótese do nosso trabalho, bem como os objetivos e as mobilizações teóricas, conseguimos verificar que a determinação dos sentidos nos recortes analisados, advindos da obra "Pela Mulheres Indígenas" (2015), apontam para a manutenção de determinadas memórias de subalternidade em relação às mulheres indígenas. Mesmo estando incluídas na ordem do discurso social, elas ainda são discursivizadas como marginalizadas, como sujeitos que buscam ser reconhecidos na sua diferença, na sua singularidade, sem que sejam discriminadas ou observadas como desiguais, seja pelo seu locus de enunciação, seja pelo seu fenótipo.

Em relação a isso, os postulados teóricos conseguiram nos auxiliar no exercício analítico das materialidades dos dois recortes, apontando que o gesto transdisciplinar torna-se uma 
estratégia teórico-metodológica que pode contribuir para as a apreensão de determinados efeitos sentidos, como os articulados nos recortes R1 e R2. Foram constatados fragmentos de histórias sofridas, situações insuportáveis que, interdiscursivamente, remetem as mulheres indígenas aos trajetos de exclusão social e que sustentam as dicotomias, as diferenças fronteiriças e os aspectos (pós-)coloniais. A mulher indígena é representada discursivamente nos recortes analisados como uma subjetividade fronteriza que ainda está fora das engrenagens da inclusão social.

Além disso, vemos que em R1 e R2, por mais que o enunciador deixa resvalar a presença das relações de poder e da (in)visibilidade outorgada e ele, denunciando o quanto os sujeitos indígenas ainda estão submersos no longo processo sacrificial que os seus povos sofreram e têm sofrido. Nessa esteira, a colonização parece que continua a operar, mas por outros mecanismos, estratégias, micropoderes, enfatizando a separação de uma maneira tão real quanto no próprio período colonial, pois na medida em que os sujeitos periféricos (sub-humanos) se veem como negados, "esquecidos" pelo Estado ou invisibilizados, a manutenção da diferença e da segregação fortalece a relação de discriminação e de preconceito em relação à identidade do sujeito indígena.

Pelos excertos analisados, parece-nos que uma obra como a "Pelas Mulheres Indígenas" pode funcionar como um dispositivo institucional que (de)marca rastros dos processos de identificação sobre as indígenas, e (re)forçando a permanência do discurso colonial, como um mecanismo subjetivador que busca controlar a representação identitária de sujeitos que mesmo falando de si ainda estão submetidos às engrenagens da (in)(ex)clusão da sociedade hegemônica.

\section{REFERENNCIAS}

AGAMBEN, G. Homo Sacer: o poder soberano e a vida nua I. Trad.: Henrique Burigo. 2. ed. Belo Horizonte: Editora UFMG, 2010.

ANZALDÚA, G. La conciencia de la mestiza / rumo a uma nova consciência. Estudos Feministas, Florianópolis, 13(3): 320, setembro-dezembro/2005, p. 704-719.

CORACINI, M. J. A análise do discurso na lingüística aplicada. In: CASTRO, S. T. R. de. (Org.). Pesquisas em lingüística aplicada: novas contribuições. Taubaté: Cabral, 2003, p. 17-33.

A celebração do outro: arquivo, memória e identidade: língua (materna e estrangeira), plurilinguismo e tradução. Campinas: Mercado de Letras, 2007.

Transdisciplinaridade e análise de discurso: migrantes em situação de rua.

Cadernos de Linguagem e Sociedade, 11 (1), 2010, 91-112. 
DERRIDA, J. O Monolinguismo do Outro. Ou a prótese de origem. Trad. Fernanda Bernardo. Porto: Campo das Letras, 1991.

. Mal de arquivo. Trad. Claudia de M. Rego. Rio de Janeiro: Relume Dumará, 2001.

Anne Dufourmantelle convida Jacques Derrida a falar da hospitalidade. Trad.: Antonio Romane. São Paulo: Escuta, 2003.

Gramatologia. Trad. Miriam Schnaiderman; Renato J. Ribeiro. São Paulo: Perspectiva e Editora da Universidade de São Paulo, 2013.

FOUCAULT, M. História da sexualidade: a vontade de saber. Trad. Maria Thereza da C. Albuquerque; J. A. Guilhon Albuquerque. 18. ed. Rio de Janeiro: Graal, 1988.

. Ditos e escritos, volume V: ética, sexualidade, política. Trad.: Elisa Monteiro; Manoel Motta. Rio de Janeiro: Forense Universitária, 2008.

Em defesa da sociedade: curso no Collège de France (1975-1976). Trad. Maria Ermantina Galvão. 2. ed. São Paulo: Martins Fontes, 2010.

Ditos e escritos, volume IV: estratégia, poder-saber. Organização e revisão Manuel B. da Motta; Trad. Lucia A. Ribeiro. 3. ed. Rio de Janeiro: Forense Universitária, 2012.

Arqueologia do saber. Trad. Luiz Felipe Neves. Rio de Janeiro: Forense Universitária, 2008.

GREGOLIN, M. do R. AD: descrever - interpretar acontecimentos cuja materialidade funde linguagem e história. In: NAVARRO, P. Estudos do texto e do discurso: mapeando conceitos e métodos. São Carlos: Claraluz, 2006, p. 19-34.

GUERRA, V.M.L. O indígena de Mato Grosso do Sul. São Carlos: Pedro \& João, 2010. UFMS, 2015.

Povos indígenas: identidade e exclusão social. Campo Grande: Editora da

MIGNOLO, W. D. Histórias locais/ projetos globais: colonialidade, saberes subalternos e pensamento liminar. Trad. Solange Oliveira. Belo Horizonte: Editora da UFMG, 2003. 
Desobediência epistêmica: a opção descolonial e o significado de identidade em política. Cadernos de Letras da UFF - Dossiê: Literatura, língua e identidade, no 34, p. 287-324, 2008.

NEVES, M. H.de M. Gramática de usos do português. São Paulo: Editora UNESP, 2000

NOLASCO, E, C. Culturas do contemporâneo: projetos locais/ leituras globais. Campo Grande: Editora da UFMS, 2009.

Perto do coração selbaje da crítica fronteriza. São Carlos: Pedro \& João,

2013.

Os condenados da fronteira. In: GUERRA, V. M. L; NOLASCO, E. C. (Orgs.). Michel Foucault: entre o passado e o presente, 30 anos de (des)locamentos. Campinas: Pontes, 2015, p. 173-184.

ONG THYDÊWÁ. (Org.). Pelas Mulheres Indígenas. $22^{\circ}$ título da coleção Índios na visão dos Índios. Secretaria de Políticas para as Mulheres da Presidência da República (SPM-PR) e da Secretaria de Políticas Públicas do Estado da Bahia (SPM-BA), 2015.

ORLANDI, E. Discurso e leitura. Campinas: Editora da UNICAMP, 2003.

PÊCHEUX, M. Semântica e discurso: uma crítica à afirmação do óbvio. Trad. Eni Orlandi et al. Campinas: Editora da Unicamp, 1988.

O discurso: estrutura ou acontecimento. Trad. Eni Puccinelli Orlandi. 6.ed. Campinas: Pontes, 2012.

POSSENTI, S. Observações sobre interdiscurso. Revista Letras, Curitiba: Editora UFPR, n. 61, especial, p. 253-269, 1988.

POTIGUARA, E. Metade cara, metade máscara. São Paulo: Global, 2004.

ROUDINESCO, E. Filósofos na tormenta. Trad. André Telles. Rio de Janeiro: Zahar, 2007.

SOUSA SANTOS, B. de. Os direitos humanos na zona de contato entre globalizações rivais, Cronos, v. 8, n.1, p. 23-40, 2007.

Direitos humanos: o desafio da interculturalidade. Revista Direitos Humanos, v.2, p. 10-18, 2008. 
Para além do pensamento abissal. Das linhas globais a uma ecologia dos saberes. In: SOUSA-SANTOS, B. de; MENEZES, M, P. (Orgs.). Epistemologias do sul. 2. ed. Coimbra: Almedina, 2010. p. 23-72.

O direito dos oprimidos: sociologia crítica do direito, parte 1. São Paulo: Cortez, 2014.

O fim do império cognitivo: a afirmação das epistemologias do Sul. Belo Horizonte: Autêntica, 2019.

**Vania Maria Lescano Guera é doutora em Linguística e Língua Portuguesa pela Universidade Estadual Paulista "Júlio de Mesquita Filho", UNESP de Araraquara, e Pós-doutorado em Linguística Aplicada pelo IEL, UNICAMP. É membro do GT "Práticas Identitárias em Linguística Aplicada" da ANPOLL, da ALAB, da ALED (Sociedade Latino-americana de Estudos de Discurso). Atualmente é docente permanente do Programa de Pós-graduação em Letras da UFMS, campus de Três Lagoas, e do Programa de Pós-graduação em Estudos de Linguagens da UFMS, campus de Campo Grande, orientando pesquisas no mestrado e doutorado. DOI - https://orcid.org/0000-0001-8361-2106.

*Willian Diego de Almeida é doutor em Letras, da área de concentração em Estudos Linguísticos e da linha de pesquisa "Discurso, subjetividades e ensino de Línguas", pela Universidade Federal de Mato Grosso do Sul, com período sanduíche na Universidade de Coimbra, no Centro de Estudos Sociais (CES) e na Faculdade de Economia da Universidade de Coimbra (FEUC). Tem experiência na área de Letras, com ênfase em Língua Portuguesa e Análise do Discurso de perspectiva francesa, em linguagem jurídica e em metodologia de ensino e pesquisa. DOI - https://orcid.org/0000-0002-4046-3427 